\title{
Erratum to: Introduction: Rabindranath Tagore and an 'Ambivalent' Nationalism
}

\author{
K.L. Tuteja and Kaustav Chakraborty
}

\section{Erratum to:}

Chapter 1 in: K.L. Tuteja and K. Chakraborty (eds.), Tagore and Nationalism, https://doi.org/10.1007/978-81-322-3696-2_1

The original version of Chapter 1 has been updated and corrected with the addition of citations and appropriate text revisions in the section "Contemporary Relevance of Tagore and His Idea of Nationalism". 